\title{
OVERVIEW OF THE DOE STUDIES OF RECOVERY BOILER FLOOR TUBE CRACKING
}

J. R. Keiser, B. Taljat, X.-L. Wang, R. W. Swindeman,

L. E. Meyers†, P. J. Maziasz, and R. L. Thomasł

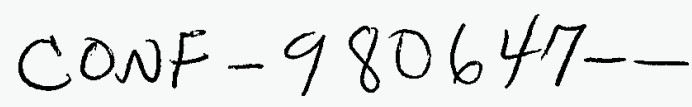

Oak Ridge National Laboratory

Oak Ridge, Tennessee 37831 United States

D. L. Singbeil and R. Prescott

Pulp and Paper Research Institute of Canada

Vancouver, British Columbia V6S 2L9 Canada

J. P. Gorog

Weyerhaeuser Company

Tacoma, Washington 98477 United States

P. M. Singh

Institute of Paper Science and Technology

Atlanta, Georgia 30318 United States

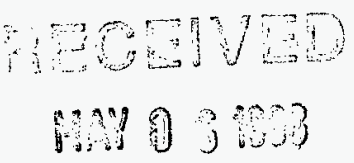

(3)

\section{ABSTRACT}

Cracking of the stainless steel layer of coextruded 304L/SA210 recovery boiler floor tubes has been observed in an increasing number of black liquor recovery boilers. Because failure of such tubes is a serious safety concern as well as an economic issue, this project was initiated with the objective of identifying alternate materials or process changes that would prevent tube cracking. Tensile stresses are essential for the most likely failure mechanisms, i.e., fatigue or stress corrosion cracking, therefore stresses were measured at room temperature and modeling was used to predict stresses under operating conditions. Laboratory studies have identified conditions under which composite tubes crack due to thermal fatigue and stress corrosion. Floor tube temperature measurements have defined the magnitude and frequency of temperature fluctuations experienced by such tubes, and smelt corrosion studies have measured the degradation rate when molten smelt comes in contact with tubes. Based on these observations, certain materials appear more likely to resist cracking and certain process changes should help avoid conditions that cause composite tube cracking.

\section{INTRODUCTION}

As described in a report summarizing the history of composite tube usage in recovery boilers [1], coextruded or composite tubes were developed and first installed in Scandinavian recovery boiler walls to mitigate the effects of higher operating temperatures on the sulfidation rate of carbon steel. In Scandinavia, the first complete wall panels of composite tubes were installed in 1972, and composite tubes were applied to recovery boiler floors in 1978. The switch to composite tubes occurred somewhat later in North America. The first application of composite wall tubes in North America occurred in 1978 and it was the mid-1980s before composite floor tubes were widely used.

$\uparrow$ Currently a student at Georgia Institute of Technology, Atlanta, Georgia

¥ Currently a student at California Polytechnic State University, San Luis Obispo, California

"The submitted manuscript has been authored by a contractor of the U.S. Government under contract No. DEAC05-96OR22464. Accordingly, the U.S. Government retains a nonexclusive, royalty-free license to publish or reproduce the published forms of this contribution, or allow others to do so, for U.S. Government purposes."

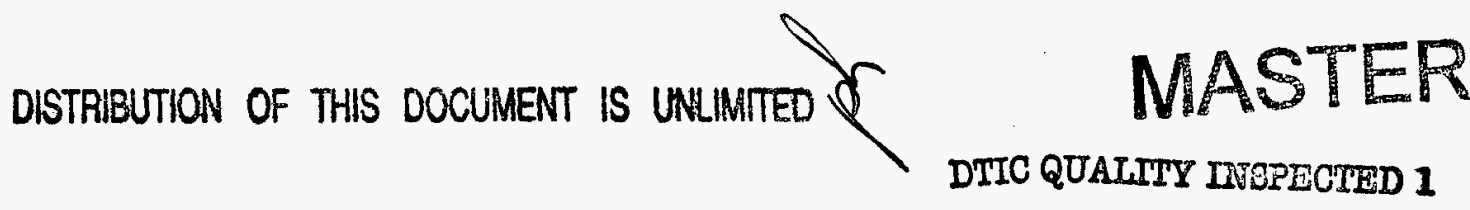




\section{DISCLAIMER}

This report was prepared as an account of work sponsored by an agency of the United States Government. Neither the United States Government nor any agency thereof, nor any of their employees, makes any warranty, express or implied, or assumes any legal liability or responsibility for the accuracy, completeness, or usefulness of any information, apparatus, product, or process disclosed, or represents that its use would not infringe privately owned rights. Reference herein to any specific commercial product, process, or service by trade name, trademark, manufacturer, or otherwise does not necessarily constitute or imply its endorsement, recommendation, or favoring by the United States Government or any agency thereof. The views and opinions of authors expressed herein do not necessarily state or reflect those of the United States Government or any agency thereof. 
Addition of the more corrosion resistant stainless steel layer to the outer surface of the carbon steel tubes proved successful in significantly reducing sulfidation. However, there were problems associated with the use of stainless steel. Specifically, cracking of smelt spout opening tubes, floor tube membranes, and eventually, floor tubes began to occur. The possibility of failure of such tubes is a serious safety concern (explosions can occur because of the near-instantaneous evaporation of water when it contacts molten smelt) as well as an economic issue for paper mill operators. Because of the importance of this issue to the forest products industry, the U. S. Department of Energy is providing funding for a project to determine the cause of the cracking and to identify alternate materials and/or operating procedures to prevent tube cracking. This project has gained wide support among paper companies, boiler manufacturers, and tube fabricators.

Five tasks are being addressed in studies at three laboratories. The task of characterizing the problem has resulted in publication of a report giving a state-of-the-art review of composite tube cracking [1]. In addition, a large number of cracked tubes has been examined in order to develop a broad understanding of the characteristics of composite tube cracking. Tubes from boilers in both North America and Europe have been examined including tubes with exposure times that range from months to many years. Certain features have been found to be common to cracked tubing regardless of exposure site or, to some extent, the material. For comparison, unexposed tubes of conventional $304 \mathrm{~L} / \mathrm{SA} 210$ as well as a number of alternate materials have been studied.

A second task is to characterize the environment experienced by composite floor tubes. These studies include analysis of smelt; determination of the thermal environment, particularly sudden variations in the temperature; determination of variations in the strain experienced by floor tubes; and analysis of the water that contacts the tubes during water washes and boiler shutdowns. Other related studies have determined the corrosion rate of various materials in molten smelt.

A third task involves determining the type (compressive vs tensile) and magnitude of stresses developed in coextruded tubing. Because of the relatively large difference in the coefficient of thermal expansion of stainless steels versus carbon steel, the potential exists for large stresses to develop during thermal cycling. Neutron and Xray diffraction have been used to determine the stresses in single tubes from several manufacturers and in asfabricated tube panels. Stress measurements have been made on exposed panels with both uncracked and cracked tubes, and finite element modeling has been used to predict the stresses in exposed panels. Additionally, modeling has also identified alternate materials that are less likely to develop the stresses that are essential for cracking to occur.

Studies of possible cracking mechanisms include laboratory tests in environments simulating conditions in which thermal fatigue, stress corrosion cracking, or corrosion fatigue might occur.

As a result of these studies, certain materials have been identified that should be less likely than $304 \mathrm{~L} / \mathrm{SA} 210$ to experience cracking in the environment of a recovery boiler floor, and operating procedures have been defined that should help avoid some of the conditions that might promote cracking.

In this paper, we summarize the results of these studies and present some conclusions that can be drawn from these results.

\section{CHARACTERIZATION OF CRACKING IN RECOVERY BOILER FLOOR TUBES}

Cracking of 304L/SA210 coextruded, or composite, tubes was an unexpected result of exposure of these tubes as part of the floor of black liquor recovery boilers. A rather thorough summary of what was known about composite tubes, and particularly cracking of composite tubes through the early stages of this project, has already been published by some of the members of the project team [1]. Characterization studies in this report focus on the manufacture of composite tubes, the features of boilers from the various manufacturers, the areas of boilers in which cracking has been found, as well as the microstructural features of cracked composite tubes, and the properties of composite tubes. 
To gain as much knowledge as possible about composite tube cracking, a large number of cracked samples have been examined. These tubes have come from boilers in Europe and North America, and they represent exposure periods ranging from less than a year to many years. Cracks have some common features, but there are also significant differences.

Cracks in composite tubes can be primarily circumferential in nature or they may show no apparent directionality. Examples of both kinds of cracking are shown in Fig. 1 on a tube from a Scandinavian recovery boiler. This tube section was located near the edge of the floor in the region where the near-horizontal floor tubes change to a vertical orientation to form the boiler walls. Shown on the surface of the tube are parallel cracks that are roughly circumferential in orientation. Also shown on the tubes are arrays of intersecting cracks that have no apparent preferred orientation. Cross sections through some of the circumferential cracks are shown in Fig. 2, and these micrographs show that the cracks are relatively wide and fairly straight near the outer surface. As the cracks proceed through the stainless steel layer, they tend to become narrower and less straight. Near the interface the cracks turn and appear to have a tendency to run parallel to the interface.

Micrographs of cracks in the areas of the tube where there seems to be no preferred cracking orientation show wider cracks that contain a lot of corrosion product (see Fig. 3). These cracks also tend to turn and run along the interface rather than proceeding through it.

Based on the above and examination of many other cracked composite floor tubes, a number of generalizations can be made. Cracks that are detectable by dye penetrant are generally fairly wide and transgranular, have relatively little branching, and almost never continue into the carbon steel. It is not uncommon for opposite sides of a crack to have matching features suggesting that the crack was pulled open rather than having had material removed by corrosion. If the cracks reach the stainless steel-carbon steel interface, they either turn and run along the interface or they end at the interface with a corrosion pit that spreads along the interface into the carbon steel. Sometimes these cracks are nearly perpendicular to the outer surface, but more often they proceed at an angle that varies significantly from the perpendicular. Occasionally cracks run parallel to the surface or cracks go upward toward the surface from a crack along the interface (Fig. 4). Cracks in tubes that are thought to have been operated for some time after cracking occurred are often much wider and have the appearance that pieces of cracked metal or corrosion product may have been lost during cutting and polishing (Fig. 5). In addition, examination of tube surfaces at higher magnification sometimes shows much shorter, narrow, transgranular cracks, as shown in Fig. 6, that have a limited amount of branching. These cracks are not likely to be detected during a typical dye penetrant examination.

\section{POTENTIAL CAUSES OF CRACKING}

The most frequently offered explanations for cracking in composite floor tubes of recovery boilers have been thermal fatigue and stress corrosion cracking. Each of these mechanisms has certain characteristic features. Thermal fatigue requires thermal cycles of a magnitude sufficient to create stresses that exceed the yield strength of the material. Stress corrosion requires a tensile stress and a particular corrodent in sufficient concentration within a characteristic temperature range. In addition corrosion fatigue and stress assisted or accelerated corrosion are mechanisms which potentially could be operative. In both of these latter cases, tensile stresses are necessary.

\section{RESIDUAL STRESS MEASUREMENTS}

Because of the significant difference in thermal expansion coefficients of 304L stainless steel and SA210 carbon steel $\left(17.3\right.$ vs $\left.12.1 \times 10^{-6} /{ }^{\circ} \mathrm{C}\right)$, it might be expected that appreciable stresses would develop during coextruded tube fabrication, during fabrication of tube panels, and when tube panels are put into service. It is not easy to predict whether these stresses are tensile or compressive and what their magnitude would be. However, it is important to know more about the stresses because cracking mechanisms like mechanical fatigue, thermal fatigue, corrosion fatigue, and stress corrosion require tensile stresses during at least some portion of the time in order for these 
mechanisms to be active. In order to determine the stresses at the surface of coextruded tubes as well as through the tube wall, X-ray and neutron diffraction were utilized.

The results of measurements of the axial and tangential residual stresses due to coextruded tube fabrication have been reported [2]. These results showed that compressive stresses were present on the outer surface of 304L/SA210 tubing from both of the principal tube manufacturers. Studies indicate that these compressive stresses are almost certainly due to the straightening process that is the final step in tube fabrication [2]. Stress measurements have also been made on tube panels, both as fabricated and after exposure. The results for the exposed panel show that both axial and tangential stresses on the fireside surface of the tubes are tensile [3]. With regard to the mechanisms that might be responsible for the cracking in coextruded 304L/SA210 tubes, these results indicate that the necessary tensile stresses are present on the outer surface of the tubes at room temperature after the tubes have seen some service in a recovery boiler.

Residual stress measurements have also been made on coextruded tubes with other material combinations as well as chromized and weld overlaid tubes. Results show that as-fabricated coextruded tubes made with a modification of Alloy 825 on carbon steel have compressive axial stresses and tensile tangential stresses [2]. Stress measurements on chromized tubing reveal small compressive stresses at the surface in the as-produced condition [4]. Modeling studies show that the unique properties resulting from the concentration gradient in chromized tubing resulted in a compressive stress state during changes in the temperature that occur during startup and shutdowns. Measurement of stresses in tubes made with Alloy 625 weld overlay on carbon steel revealed very large tensile stresses in the as-fabricated condition [5]. These stresses were very effectively reduced by heat treatment at a temperature high enough to anneal the carbon steel and stress relieve Alloy 625 .

\section{FINTTE ELEMENT MODELING OF STRESSES}

Finite element modeling (FEM) has been used to evaluate the effects on stresses of tube fabrication, welding the tubes and membranes to form panels, subjecting the tubes to internal pressurization, and heating the tubes on one side with the intense heat experienced on the fireside in a recovery boiler [6]. The model first addressed the stress state of the tubes during normal operation and then during periods when temperatures are different from operating temperature. These periods include the heat-up when the boiler is being started, occasions during normal operation when temperature fluctuations occur, and the cool down period when the boiler is being shut-down. Results show that during the heat-up, stresses on the outer surface of the tubing change from tensile to compressive. It should be noted that, although the tubes initially had compressive stresses at the surface, panel fabrication changed the tangential or hoop stresses to tensile. Because of the relatively low yield strength of the 304L stainless steel and the significant stresses that develop because of the large thermal expansion coefficient differences, the model indicates that (compressive) stresses developed in heating from room temperature to operating temperature exceed the yield strength of the stainless steel. As a result, the outermost surface on the fireside of the tubes undergoes plastic deformation. When the tubes are cooled from operating temperature to room temperature, the stresses on the outer surface change from compressive to tensile. For a boiler tube operating at $315^{\circ} \mathrm{C}\left(600^{\circ} \mathrm{F}\right)$ this change from compressive to tensile stresses is estimated to occur somewhere around a temperature of $270^{\circ} \mathrm{C}$.

Modeling has also been done to predict the stress state during and after the time of a short duration temperature rise on small portion of a tube panel. The portion of the tube panel experiencing this temperature excursion is subjected to further compressive stresses which result in additional plastic deformation. When this temperature excursion ends and the section of the tube panel cools to operating temperature, the stresses that develop on the surface of the tubes in that limited area are tensile [7]. When the boiler is shut down, the section that experienced the temperature excursion is cooled to room temperature and higher tensile stresses develop (the cooler metal has a higher yield strength) that cause further plastic deformation. Because of the plastic deformation that occurs, reheating the tube panel to operating temperature causes the stresses on the outer surface of the tubes to become compressive. 
The conclusion from this modeling is that under normal operating conditions, the outer surface of composite tubes is in compression except for portions of tubes that have been subjected to thermal spikes or "hot spots". Tensile stresses result in these areas when cooled back to operating conditions. However, even the areas subjected to these hot spots return to a compressive stress state after the boiler is cooled to room temperature then reheated to operating temperature [8]. The results of these modeling studies are consistent with the stresses measured in exposed tube panels in that the model predicts tensile stresses at room temperature, and the stresses measured at room temperature on the fireside surface of tubes in a tube panel are compressive.

Modeling studies have also been conducted to determine the yield strength and the coefficient of thermal expansion for alloys that would not develop tensile stresses on the surface of a coextruded tube and would not develop stresses that exceeded the yield. strength. This work is described more extensively elsewhere [6], but it should be noted that, for tubes that are exposed to normal operating conditions, both Alloys 825 and 625 have properties that put them in the range for which the stress criteria are satisfied.

\section{CHARACTERIZATION OF TUBE ENVIRONMENT}

Another important consideration is being able to define the thermal and chemical environment to which floor tubes are exposed. Again, considerable work has been done to develop this information. Ideally, floor tubes are in contact with a layer of frozen smelt which should help keep the surface of the tubes at a fairly constant temperature. However, some evidence suggests otherwise. For example, failures in the early 1990s of tubes in three studded carbon steel floors showed evidence of severe thinning of the carbon steel tube wall as well as significant overheating of the carbon steel. This degradation was attributed to molten smelt coming into contact with the tubes for a relatively limited time.

There is also some question about the conventional thinking concerning the smelt composition. In one study measurements of the composition of smelt that was immediately adjacent to floor tubes showed the smelt was often enriched in sulfur, chlorine and/or potassium when compared to the average smelt composition [9]. These elements can have a significant effect on smelt properties including melting point and viscosity. Comparable results have not been reported by others, but no reports were found containing the analysis of smelt samples collected before water washing from material immediately adjacent to floor tubes. Further analyses are needed from additional samples collected under the same circumstances to gain better insight into these reported compositional variations.

The aggressiveness of smelt both of a typical composition and enriched in potassium and sulfur has been determined for several of the alloys currently in use as recovery boiler tubes. For the typical smelt, corrosion rates were measured at a temperature of $800^{\circ} \mathrm{C}$ in order to have the smelt molten. The presence of additional potassium and sulfur significantly lowered the melting point of smelt such that the second set of corrosion tests was conducted at $580^{\circ} \mathrm{C}$. It is expected that alloys containing a high nickel content performed much better at the lower temperature because of the nickel-sulfur eutectic that occurs at about $660^{\circ} \mathrm{C}$. Measured corrosion rates are shown in Table I. In both smelt compositions, carbon steel has the highest corrosion rate while Alloy 825 has the lowest rate in the typical smelt while Alloy 625 has the lowest rate in the enriched smelt.

Short duration variations in floor tube temperatures have been reported by a number of researchers [10-12]. These reports indicate that the temperature on or very near the crown of floor tubes experiences occasional spikes during which the temperature can significantly increase above normal operating temperature.

The floor of the No. 1 recovery boiler at a Saskatchewan mill has developed bowing or deflections in certain areas of the floor, particularly near the spout wall, and a deflection of several inches in one of the floor support I-beams nearest the spout wall. In order to collect information about the thermal spikes and any phenomena that might be affecting or even causing the floor tube and beam deflection, thermocouples and strain gauges were installed at five locations on composite floor tubes. The locations include points a short distance in front of three of the four smelt spout openings along with positions on tube 50 approximately 90 and $183 \mathrm{~cm}$ (36 and $72 \mathrm{in}$.) from the spout wall. At each of the five locations, a thermocouple was attached to the crown of the tube, and a strain gauge was 
attached to the opposite (vestibule) side of the tubes. The temperatures indicated by these thermocouples may be somewhat higher than experienced by the actual tube surface because the thermocouples may be raised slightly above the tube crown.

Strain gauges are attached to the vestibule side of the composite tubes in order to get some indication of the tendency for the tubes to distort during normal operation. Typical results, like those shown in Fig. 7, indicate that fluctuations in the strain often occur simultaneously with the temperature fluctuations. Some of these temperature fluctuations have a relatively small magnitude while others can change by an amount $z 150 \mathrm{C}^{\circ}$. During the first $51 / 2$ months that data were collected from the four locations, only 41 fluctuations were noted with a $\Delta \mathrm{T}$ greater than $100 \mathrm{C}^{\circ}$ and only 4 of those had a $\Delta \mathrm{T}$ greater than $150 \mathrm{C}^{\circ}$. On a few occasions, a series of low amplitude fluctuations have continued for many hours (see Fig. 8). These relatively infrequent series of fluctuations seem to occur a few weeks before it becomes necessary to water wash. On some occasions, strain changes are seen without accompanying temperature changes (see Fig. 9). Studies of operating logs reveal that these changes often coincide with changes in the number of nozzles being used to provide liquor to the boiler.

The next question is which cracking mechanism is most likely to be operative given the stress states that have been determined and the environmental conditions that have been defined? To address this question, studies have been conducted on both thermal fatigue and stress corrosion cracking behavior of coextruded 304L/SA210 tubing.

\section{BEHAVIOR OF COEXTRUDED 304L/SA210 TUBING UNDER THERMAL FATIGUE CONDITIONS}

Thermal fatigue results when cyclic strains developed by thermal cycles are sufficient to produce plastic strains. The possibility of thermal fatigue in composite tubes in black liquor recovery boilers was originally addressed by Egnell and Tornblom [13]. More recently, Swindeman and coworkers reported on studies of fatigue cracking in composite tubes and addressed the microstructural and submicrostructural evidence indicating that thermal fatigue was not likely in composite recovery boiler floors [14].

Data on thermal fatigue of 304 stainless steel, shown in Fig. 10, was collected and used to assess the likelihood that temperature fluctuations in recovery boiler tubes could cause sufficient damage to result in cracking. These results indicate that the strain resulting from a temperature variation from 300 to $450^{\circ} \mathrm{C}$ would require in excess of 100,000 cycles to reach the design curve for that alloy. For a temperature variation of 300 to $540^{\circ} \mathrm{C}$, a region of a tube would have to experience this transient 10,000 or more times for fatigue to occur. Based on temperature measurements reported in this paper and by others [10-12], there is no indication that any section of floor tubing accumulates this number of cycles.

Exposure to tens of thousands of cycles to such elevated temperatures would result in the accumulation of significant time at the elevated temperature. Microstructural studies of samples aged at such temperatures show that considerable precipitation occurs on the stainless steel-carbon steel interface. Examination of the interface in exposed tubes with cracks seldom reveals any detectable increase in the interfacial precipitates.

Both mechanical and thermal fatigue tests have been conducted in the laboratory to produce samples with the submicrostructural features characteristic of both types of fatigue. These samples have been examined with transmission electron microscopy along with samples taken from composite floor tubes that are cracked as the result of exposure in a recovery boiler floor. Each type of fatigue produces a characteristic dislocation structure, and these have been compared to the structure found in a number of previously exposed (both cracked and not cracked) tubes. The consistent observation is that the exposed tubes have a dislocation structure indicative of exposure to thermal cycles but not in sufficient frequency to cause thermal fatigue [14]. 
SCC can result when very localized corrosion occurs in the presence of a tensile stress. It is generally restricted to metals and alloys which exhibit active-passive behavior in the presence of the corroding environment. The presence of a liquid phase in contact with the surface of the metal, although not necessarily water, is a requirement for this mechanism. Consequently, efforts to show whether or not SCC may be a cause of floor tube cracking have focused on environments known to be liquid during operation of a recovery boiler, or on determining the conditions under which a liquid phase may be present.

Based on thermodynamic studies of the salts present in smelt [15], there is little chance that a liquid phase could be in contact with the surface of the floor tubes during normal boiler operation. The lowest possible melting point of a solid with the constituents of smelt is about $500^{\circ} \mathrm{C}$, and the surface temperature of floor tubes should not approach such a temperature unless the tubes were subject to extremely high, and unusual, heat fluxes. Analyses of smelt removed from the bed of a boiler have indicated significant stratification from the surface to the bottom of the bed. In particular, the layer of smelt in immediate contact with the floor tubes was enriched in potassium and sulphur. This has led to speculation that polysulfide salts, with a melting point of just over $300^{\circ} \mathrm{C}$, may be present on boiler floors $[9,15-17]$. Confirmation of the existence of such a liquid phase in contact with boiler floors at operating temperatures remains elusive. Although at present it cannot be ruled out, SCC during operation appears unlikely.

Tests to evaluate the likelihood that water washing might be the cause of SCC were conducted in Finland [18]. SCC was observed in some of the tests at $80^{\circ} \mathrm{C}$ in a solution of dissolved smelt adjusted to $\mathrm{pH} 10$ with hydrochloric acid, but the authors attributed the cracking to the combination of added chloride and lower $\mathrm{pH}$, an environment known to cause SCC in austenitic stainless steels. No SCC occurred in similar tests conducted at pH 13 and the authors concluded that SCC of co-extruded floor tubes in recovery boilers was unlikely to occur during waterwashing itself, although they speculated that concentration of salts during boiler shut-downs or start-ups might cause SCC.

Recently, the influence of sodium sulfide $\left(\mathrm{Na}_{2} \mathrm{~S}\right)$, sodium hydroxide $(\mathrm{NaOH})$, and sodium carbonate $\left(\mathrm{Na}_{2} \mathrm{CO}_{3}\right)$ on $\mathrm{SCC}$ of $304 \mathrm{~L}$ stainless steel at temperatures up to $250^{\circ} \mathrm{C}$ has been explored [19]. All of these compounds are present in significant amounts in the smelt bed, and may be found in the remnants of the bed adjacent to the surface of the tubes, even after water washing. $\mathrm{Na}_{2} \mathrm{~S}$ is strongly hygroscopic, and exists at ambient temperatures as a hydrated salt. It may exist as a hydrated liquid at temperatures as high as about $180^{\circ} \mathrm{C}$, and the presence of $\mathrm{NaOH}$ appears to increase the persistence of the liquid phase to higher temperatures. Stress corrosion tests with Ubend specimens showed that $304 \mathrm{~L}$ stainless steel is extremely susceptible to SCC at temperatures in the range of $160-250^{\circ} \mathrm{C}$ when exposed to pure $\mathrm{Na}_{2} \mathrm{~S}$, or mixtures of $\mathrm{Na}_{2} \mathrm{~S}$ and $\mathrm{NaOH}$, or $\mathrm{Na}_{2} \mathrm{~S}$ and $\mathrm{Na}_{2} \mathrm{CO}_{3}$, as long as the salt remained liquid. Crack propagation was very rapid in these salts, and it is speculated that their presence on the surface of the floor tubes during a dry-out fire, or the boiler warm-up after a water-wash may be the cause of SCC.

As part of a larger effort to clarify the role of these salts in producing SCC of boiler floor tubes, tests in one such salt mixture were conducted on C-rings made from a number of candidate materials for the outer layer of coextruded tubes. The $\mathrm{C}$-rings were cut from lengths of composite tube, immersed in salt mixtures and heated. The tests were carried out in a $\mathrm{Na}_{2} \mathrm{~S} \cdot 9 \mathrm{H}_{2} \mathrm{O}-25 \% \mathrm{NaOH}$ salt mixture for 68 hours at $220^{\circ} \mathrm{C}$. Small volumes of water $\left(10 \mathrm{~cm}^{3}\right)$ were added to the salt mixture twenty times during the course of the test to ensure that the salt mixture did not become dehydrated.

Based on observations of crack depth and the number of cracks per unit length of metal surface, the following observations can be made.

- Type 304L stainless steel is highly susceptible to this type of stress corrosion. The cracks progressed all the way through the outer layer to the interface with the carbon steel core, a distance of about $1.6 \mathrm{~mm}$. The cracks were transgranular and branched and similar to the fine, narrow cracks observed in tubes removed from operating recovery boilers. 
- Type 309L stainless steel appears to have only marginally better resistance to stress corrosion cracking than type 304L. Less branching was observed, nevertheless, the cracks progressed to the interface with the carbon steel.

- Type 310 stainless steel is considerably more resistant than types $304 \mathrm{~L}$ and $309 \mathrm{~L}$. Cracking did occur, but the cracks were much shorter $(50 \mu \mathrm{m}$ instead of $1.6 \mathrm{~mm})$ and less numerous.

- Sanicro 38 (Alloy 825) was even more resistant to cracking than type 310 stainless. However, tiny cracks (roughly $10 \mu \mathrm{m}$ in length) were detected, proving that this material is clearly not immune to stress corrosion in this environment.

- Alloy 625 did not show any cracks under these test conditions and is apparently more resistant than the other materials tested. It is not clear whether this material would be susceptible to cracking under more severe conditions (e.g. longer exposure, higher temperature, increased circumferential tensile stress).

- No cracking of the carbon steel took place when stress corrosion cracks penetrated to the interface in Crings made from composite tubes of types $304 \mathrm{~L}$ and 309L stainless steel, or when a carbon steel C-ring was immersed in the salt, although carbon steel is known to be susceptible to SCC in strongly alkaline environments.

\section{SUMMARY AND RECOMMENDATIONS}

This project, by utilizing the research capabilities of the Pulp and Paper Research Institute of Canada, the Institute of Paper Science and Technology, and the Oak Ridge National Laboratory, has contributed significantly to understanding the cracking in composite floor tubes in black liquor recovery boiler floors. The information about composite tube cracking that was available at the time this project was initiated has been summarized in a report. A large number of cracked tubes have been examined, and the typical pattern, as well as the extremes, have been characterized.

Because tensile stresses are essential for all of the proposed cracking mechanisms, the stress state of composite floor tube panels was determined at room temperature from X-ray and neutron diffraction measurements and was predicted for operating conditions from finite element analysis. These studies indicate that compressive stresses are present on the surface of floor tubes during normal operation. Tensile stresses are present during a shutdown when the tubes are cooled and at operating temperature in a localized area that has experienced a hot spot or temperature fluctuation to higher temperature.

Efforts to characterize the thermal environment using thermocouples on recovery boiler floors show that the tubes do experience thermal spikes, but these occur relatively seldom.

Fatigue studies show that cracks can be initiated in a few thousand cycles if a combination of mechanical and thermal stresses are applied, but these same studies strongly suggest that thermal fatigue is not likely to be responsible for cracking in composite tube floors. This observation is supported by transmission electron microscopy studies comparing the microstructures of fatigued samples with those of cracked floor tubes. These microstructures indicate that floor tubes, both cracked and uncracked, have been exposed to a significant number of thermal cycles but not enough cycles to cause thermal fatigue cracking.

Stress corrosion cracking studies using various liquid phases that are presumed likely to be present on a recovery boiler floor during a water wash or a shutdown have shown that cracking can occur in some of these environments. Specifically, hydrated sodium sulfide, by itself, or in combination with sodium hydroxide or sodium carbonate, has been shown to cause cracking of $304 \mathrm{~L}$ stainless steel in the $160-250^{\circ} \mathrm{C}$ temperature range. Cracking of higher nickel alloys (Alloy 825 and Alloy 625 ) in this environment seems to decrease proportionately with the increase in nickel content. 
Information is not sufficient to definitively say that hydrated sodium sulfide is the cause of cracking in recovery boiler floor tubes. The information does indicate that floor tube cracks are almost certainly initiated by a stress corrosion cracking mechanism; sodium sulfide could be the corrodent involved. The tubes do experience thermal cycling, and this cycling would cause tensile stresses that could tend to open the stress corrosion cracks.

Based on this information, the following recommendations are made:

- To the greatest extent possible, minimize thermal fluctuations experienced by floor tubes. This would include keeping the bed as stable as possible and keeping the size of falling salt cake pieces as small as possible.

- $\quad$ As much as possible, avoid leaving wash water in contact with the floor especially during periods when the floor tubes are heated to temperatures in the $150-175^{\circ} \mathrm{C}$ range.

- If coextruded or weld overlay tubes are to be used on the floor, use an alloy for the outer layer that has a higher yield strength than $304 \mathrm{~L}$ stainless and a thermal expansion coefficient that more closely matches that of the carbon steel base material.

\section{REFERENCES}

1. Singbeil, D. L., Prescott, R., Keiser, J. R., Swindeman, R. W., Composite Tube Cracking in Kraft Recovery Boilers - A State-Of-The-Art Review, Proceedings of the 1997 TAPPI Engineering and Papermakers Conference, TAPPI Press, Atlanta, p. 1001.

2. Keiser, J. R., Taljat, B., Wang, X.-L., Maziasz, P. J., Hubbard, C. R., Swindeman, R. W., Singbeil, D. L., Prescott, R., Analysis of Composite Tube Cracking in Recovery Boiler Floors, Proceedings of the 1996 TAPPI Engineering Conference, TAPPI Press, p. 693.

3. Keiser, J. R., Taljat, B., Wang, X.-L., Swindeman, R. W., Maziasz, P. J., Thomas, R. L., Payzant, E. A., Singbeil, D. L., and Prescott, R., Analysis of Cracking of Co-Extruded Recovery Boiler Floor Tubes, Proceedings of the 1997 TAPPI Engineering and Papermakers Conference, TAPPI Press, Atlanta, p. 1025.

4. Keiser, J. R., Hubbard, C. R., Maziasz, P. J., Swindeman, R. W., Taljat, B., Wang, X.-:L., Meyers, L. E., Singbeil, D. L, and Prescott, R., Development of Materials for Black Liquor Recovery Boilers, 1997 Annual Progress Report, Advanced Industrial Materials Program, Oak Ridge National Laboratory, to be published.

5. Wang, X.-L., Payzant, E. A., Taljat, B., Hubbard, C. R., Keiser, J. R., and Jirinec, M. J., Experimental Determination of the Residual Stresses in a Spiral Weld Overlay Tube, Mat. Sci. Eng., A232: 31 (1997).

6. Taljat, B., Zacharia, T., Wang, X.-L., Keiser, J. R., Swindeman, R. W., and Hubbard, C. R., Mechanical Design of Steel Tubing For Use in Black Liquor Recovery Boilers, Proceedings of the $9^{\text {th }}$ International Symposium on Corrosion in the Pulp and Paper Industry, CPPA, Montreal, PQ., (1998).

7. Taljat, B., Zacharia, T., Keiser, J. R., and Wang, X.-L., Modeling Studies of Composite Tube Floor in Black Liquor Recovery Boiler, Submitted to TAPPI Journal.

8. Oral presentation by Taljat, B., Oak Ridge National Laboratory, Project Review Meeting, December 3, 1997, Cincinnati, $\mathrm{OH}$.

9. Private communication, Koivisto, L. and Kiiskilä, E., Ahlstrom Machinery Corporation, Varkaus, Finland, to Gorog, J. P., Weyerhaeuser-Tacoma, Singbeil, D.L., Pulp and Paper Research Institute of Canada, and Keiser, J. R., Oak Ridge National Laboratory. 
10. Private communication, Crowe, D. C., Union Camp Corporation, to Keiser, J. R., Oak Ridge National Laboratory.

11. Oral presentation by LeBel, M. P., ABB CE Services, Project Review Meeting, August 22, 1966, Laurel, MD.

12. Private communication, Wood, M. R., Georgia-Pacific Corporation, to Keiser, J. R., Oak Ridge National Laboratory and Singbeil, D. L., Pulp and Paper Research Institute of Canada.

13. Egnell, L. and Tornblom, H., Thermal Fatigue in Composite Tubes, paper C238/73 in Joint International Conference on Creep and Fatigue in Elevated Temperature Applications, Institute of Mechanical Engineers, London, UK (1973).

14. Swindeman, R. W., Fatigue of Austenitic Stainless Steels in the Low and Intermediate Cycle Range, ORNL-TM1363, Oak Ridge National Laboratory, Oak Ridge, TN (1966).

15. Mäkipää, M., Mäkinen, S., Backman, R., and Hämäläinen, M., Corrosion of BLRB Floor Tubes in Reduced Kraft Smelts: Experimental and Theoretical Studies, Proceedings of 1996 TAPPI Engineering Conference, TAPPI Press, p. 681.

16. Klarin, A., Floor Tube Corrosion in Recovery Boilers, Tappi Journal, 76(12):183 (1993).

17. Private communication, Hupa, M., and Backman, R., Åbo Akademi University, Turku, Finland, to Gorog, J. P., Weyerhaeuser-Tacoma, Singbeil, D. L., Pulp and Paper Research Institute of Canada, and Keiser, J. R., Oak Ridge National Laboratory.

18. Pohjanne, P., Hanninen, H., Mäkipää, M., and Ehrnsten, U., Cracking of Compound Tubes in Black Liquor Recovery Boilers, Proceedings of the $7^{\text {th }}$ International Symposium on Corrosion in the Pulp and Paper Industry, Tappi Press, Atlanta p. 319 (1992).

19. Prescott, R., Eng, P., and Singbeil, D. L., Stress-Corrosion Cracking of Type 304L Stainless Steel in Kraft Recovery Boiler Environments, Proceedings of the $9^{\text {th }}$ International Symposium on Corrosion in the Pulp and Paper Industry, CPPA, Montreal, PQ., (1998).

\section{ACKNOWLEDGMENTS}

The authors would like to thank S. J. Pawel and J. R. DiStefano for reviewing the document. The efforts of H. F. Longmire in preparing and photographing the many metallographic samples is gratefully acknowledged. P. Eng provided technical support for stress corrosion C-ring tests. The cooperation and contributions from various paper companies, mill personnel, boiler manufacturers, tube fabrications, and inspection companies are sincerely appreciated. This research was sponsored by the U.S. Department of Energy, Assistant Secretary for Energy Efficiency and Renewable Energy, Office of Industrial Technologies, Advanced Industrial Materials Program, under contract DEAC05-96OR22464 with Lockheed Martin Energy Research Corp. 
Table I. Corrosion rates of selected alloys in typical smelt and smelt enriched in potassium and sulfur.

\begin{tabular}{|l|c|c|}
\hline \multicolumn{1}{|c|}{ Alloy } & $\begin{array}{c}\text { Corrosion Rate in Typical Smelt } \\
\text { at } 800^{\circ} \mathrm{C} \\
\mathrm{mm} / \mathrm{yr}(\mathrm{mpy})\end{array}$ & $\begin{array}{c}\text { Corrosion Rate in Enriched Smelt } \\
\text { at } 580^{\circ} \mathrm{C} \\
\mathrm{mm} / \mathrm{yr}(\mathrm{mpy})\end{array}$ \\
\hline SA210 carbon steel & $82.36(3243)$ & $103.38(4070)$ \\
\hline 304L stainless steel & $17.37(684)$ & $77.04(3033)$ \\
\hline Alloy 825 & $14.53(572)$ & $64.62(2544)$ \\
\hline Alloy 625 & $54.79(2157)$ & $59.99(2362)$ \\
\hline
\end{tabular}

Figure captions

Figure 1. Section of tube from Scandinavian recovery boiler showing circumferential and craze cracking.

Figure 2. Cross section of composite tube showing circumferential cracks.

Figure 3. Cross section of composite tube showing craze cracks.

Figure 4. Cross sections of composite tube showing crack running parallel to the surface and cracks originating at an interfacial crack.

Figure 5. Cross section of composite tube showing very wide cracks from which considerable material has apparently been lost.

Figure 6. Examples of short, narrow, transgranular cracks often found at the surface of composite tubes.

Figure 7. Strain gauge and thermocouple indications for typical fluctuation detected on recovery boiler floor.

Figure 8. Example of a series of low amplitude fluctuations in strain and temperature detected on a recovery boiler floor.

Figure 9. Example of strain change without a temperature change seen with strain gauge and thermocouple on a recovery boiler floor tube.

Figure 10. Thermal fatigue data for 304 stainless steel showing the ASME design curve along with results for cycles to higher temperatures. 

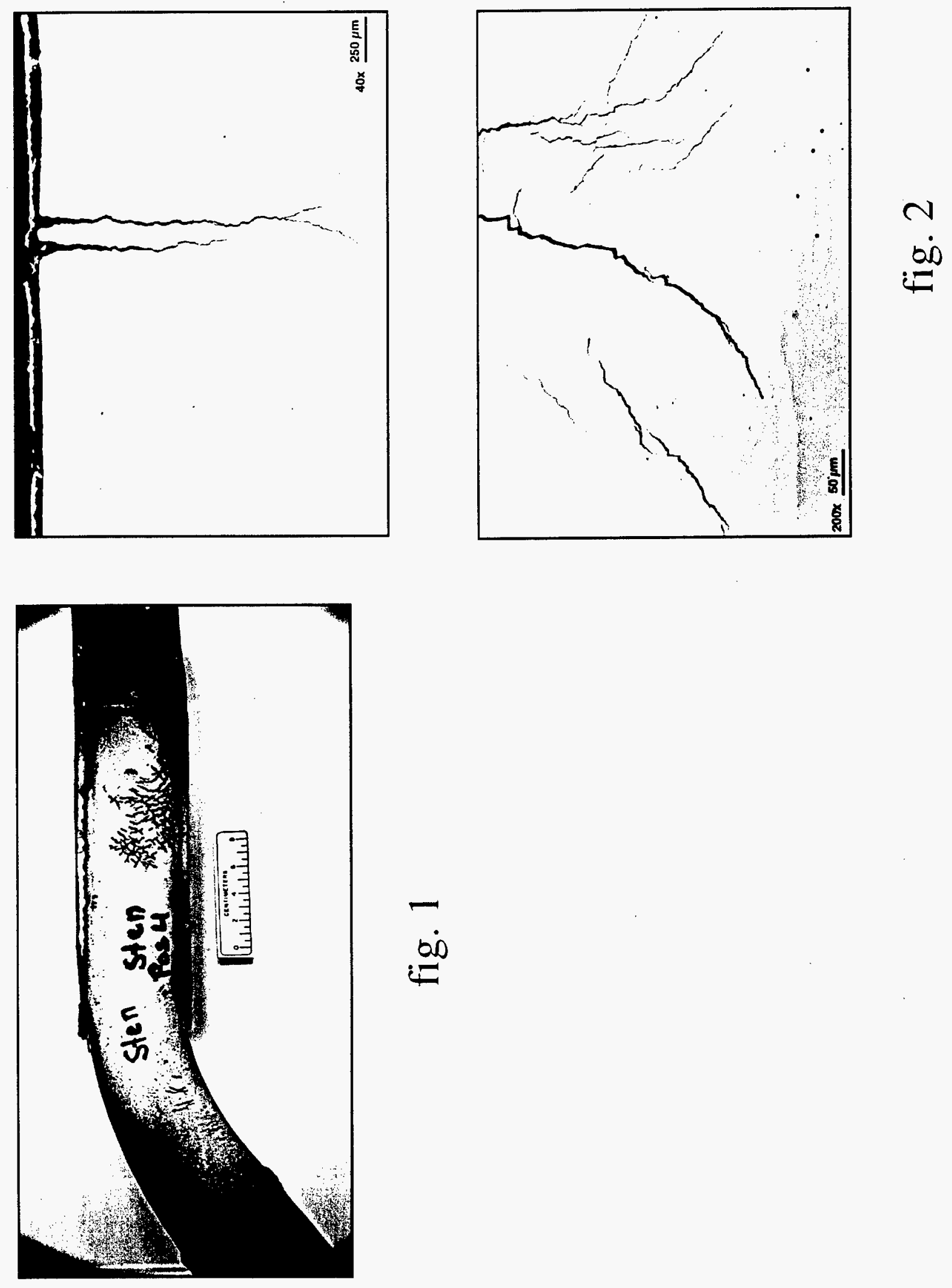

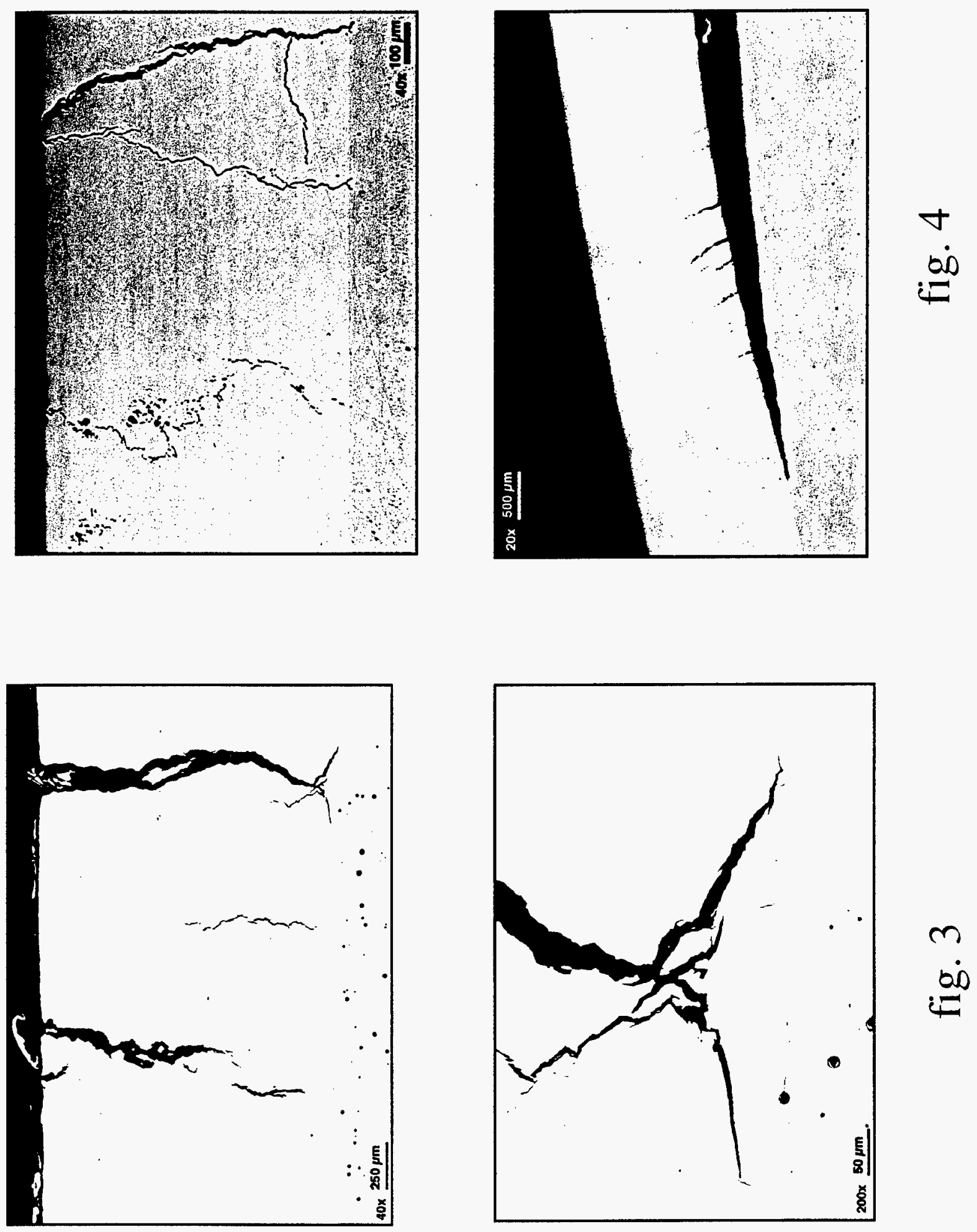


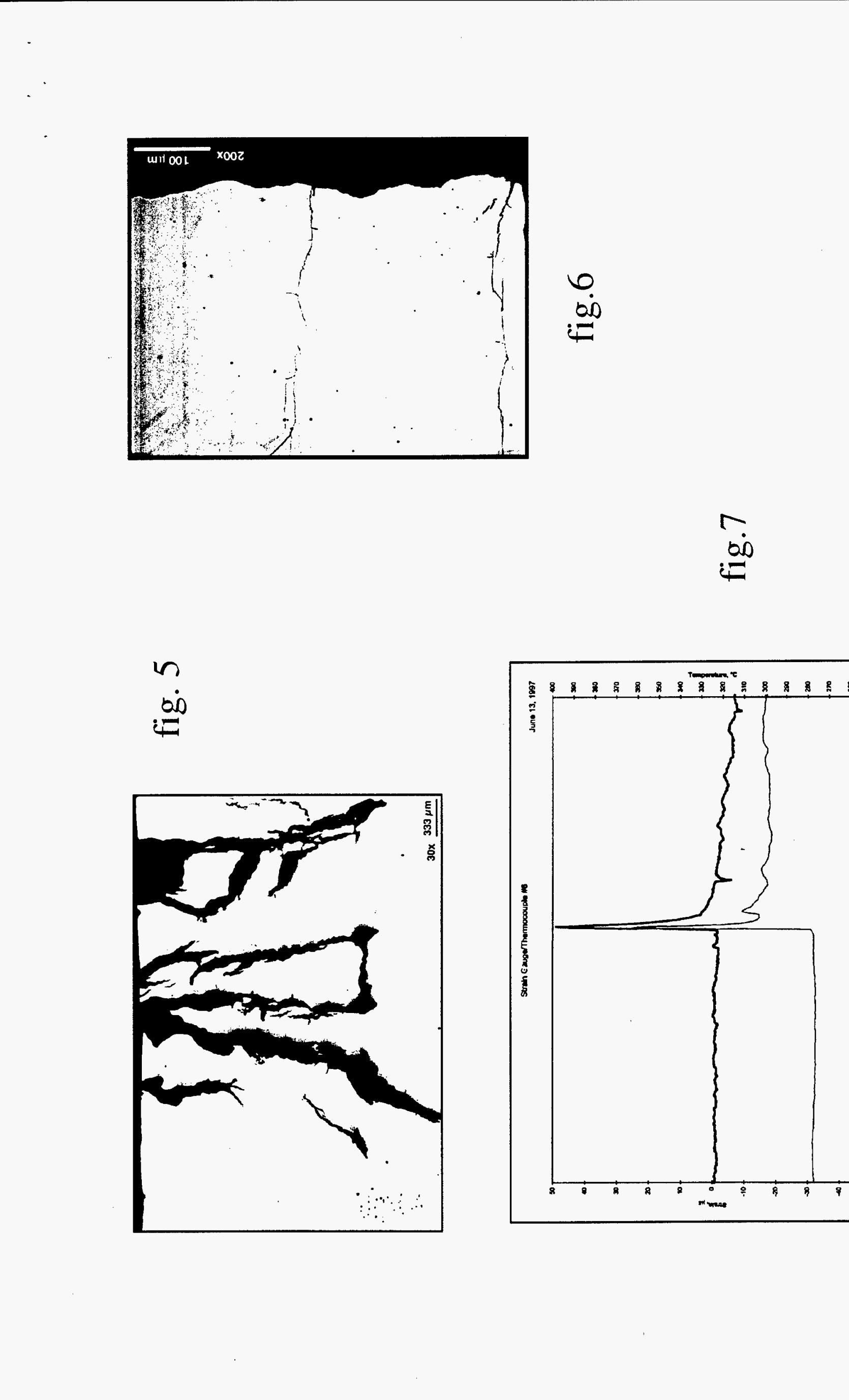


$\infty$

in
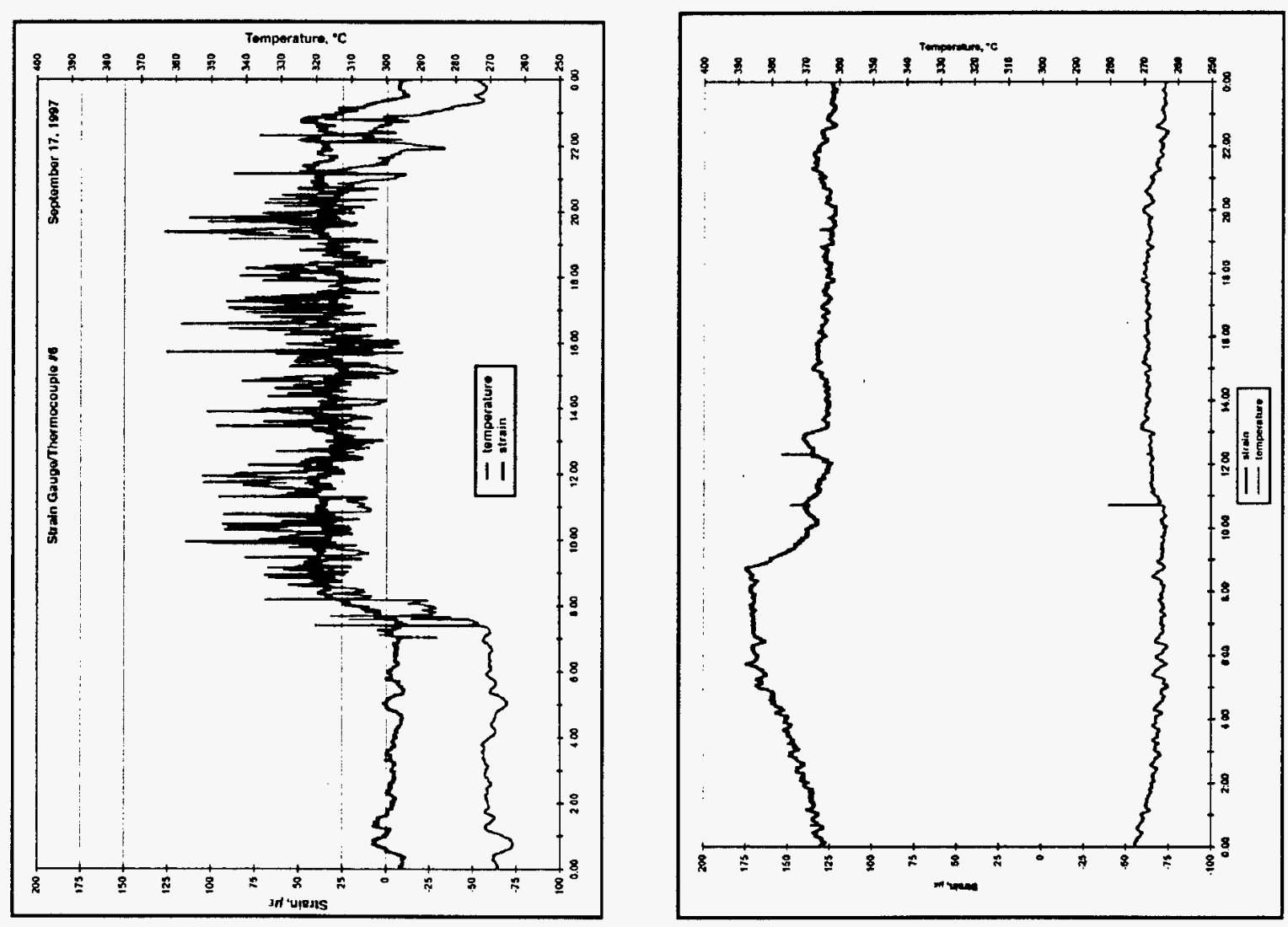


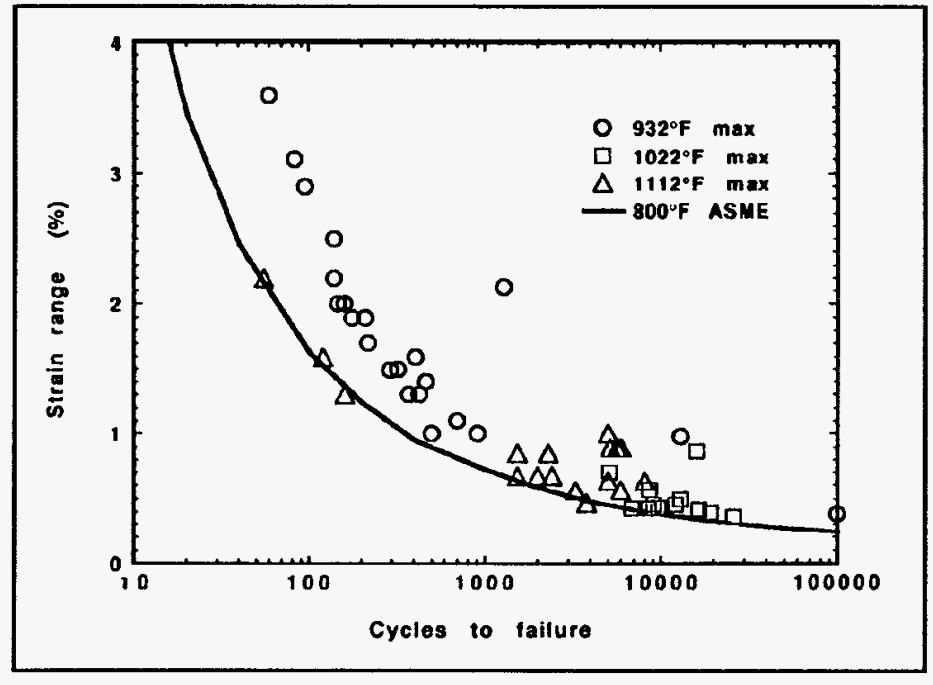

fig. 10 


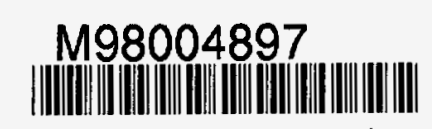

Report Number (14) ORNL/CP ..97302

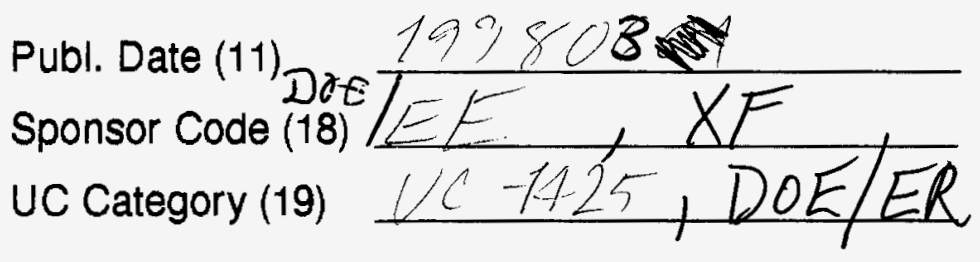

